
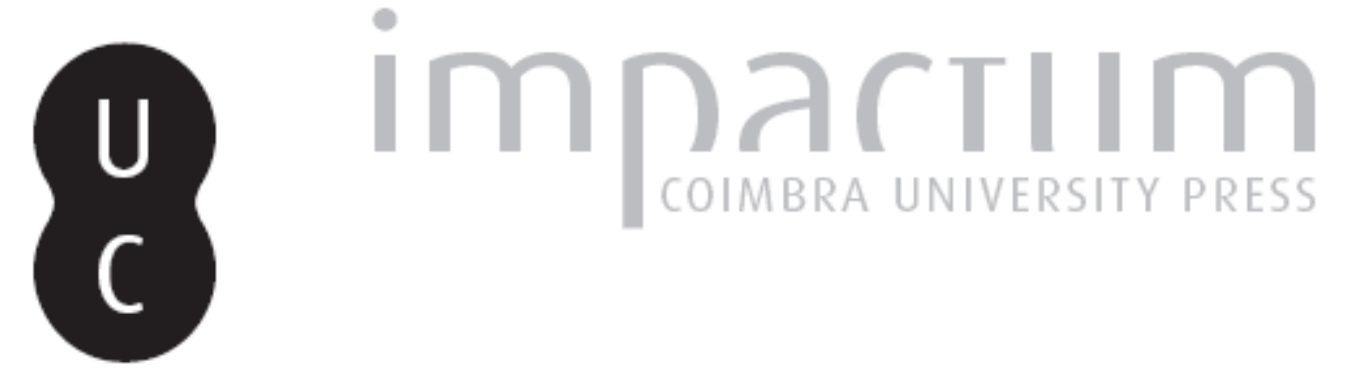

\title{
[Recensão a] SOUZA, E. DE (2013). CATÁBASES: ESTUDOS SOBRE AS VIAGENS AOS INFERNOS NA ANTIGUIDADE
}

\author{
Autor(es): $\quad$ Serra, Ordep José Trindade
}

Publicado por: Annablume Clássica; Imprensa da Universidade de Coimbra

URL persistente:

URI:http://hdl.handle.net/10316.2/36133

DOI:

DOI:http://dx.doi.org/10.14195/1984-249X_14_11

Accessed : $\quad$ 26-Apr-2023 14:57:35

A navegação consulta e descarregamento dos títulos inseridos nas Bibliotecas Digitais UC Digitalis, UC Pombalina e UC Impactum, pressupõem a aceitação plena e sem reservas dos Termos e Condições de Uso destas Bibliotecas Digitais, disponíveis em https://digitalis.uc.pt/pt-pt/termos.

Conforme exposto nos referidos Termos e Condições de Uso, o descarregamento de títulos de acesso restrito requer uma licença válida de autorização devendo o utilizador aceder ao(s) documento(s) a partir de um endereço de IP da instituição detentora da supramencionada licença.

Ao utilizador é apenas permitido o descarregamento para uso pessoal, pelo que o emprego do(s) título(s) descarregado(s) para outro fim, designadamente comercial, carece de autorização do respetivo autor ou editor da obra.

Na medida em que todas as obras da UC Digitalis se encontram protegidas pelo Código do Direito de Autor e Direitos Conexos e demais legislação aplicável, toda a cópia, parcial ou total, deste documento, nos casos em que é legalmente admitida, deverá conter ou fazer-se acompanhar por este aviso.

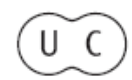




\section{4}

jan/jun

2015

issn 2179-4960 e-issn 1984-249-X
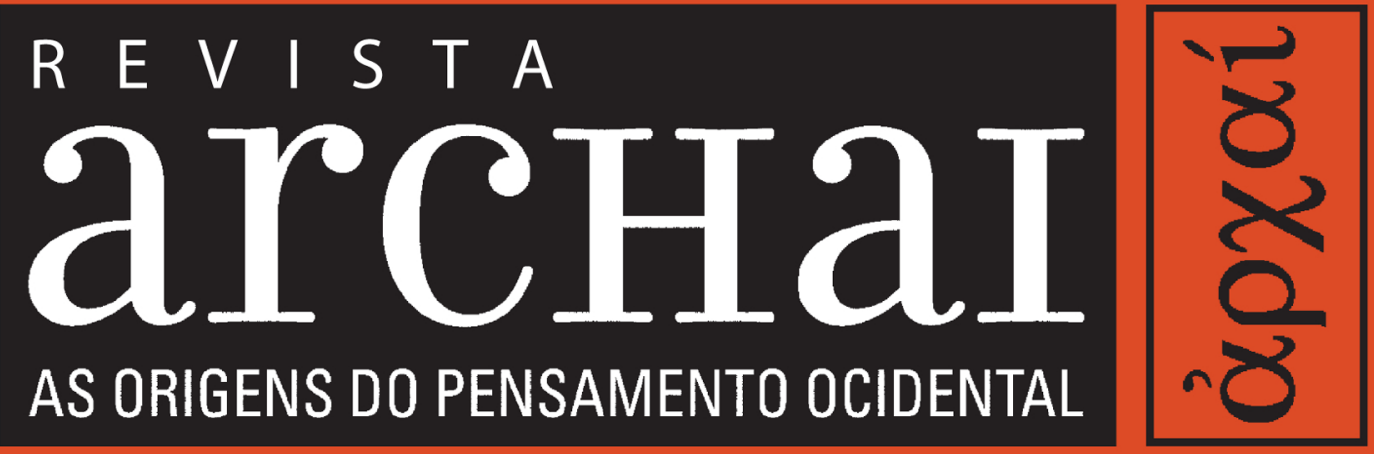

ARCHAI JOURNAL: ON THE ORIGINS OF WESTERN THOUGHT

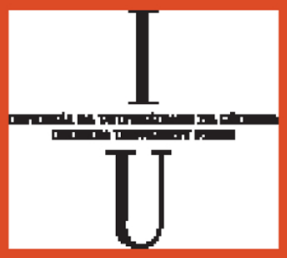

\section{archaI}

AS ORIGENS Do PENSAMENTO OCIDENTAL 


\section{SOUZA, E. DE (2013). CATÁBASES: ESTUDOS SOBRE AS VIAGENS AOS INFERNOS NA ANTIGUIDADE. SÃO PAULO. ANNABLUME CLÁSSICA.}

SERRA, 0. (2014). Resenha. SOUZA, E. DE (2013). Catábases: estudos sobre as viagens aos infernos na antiguidade. São Paulo. Annablume Clássica. Archai, n. 14, jan - jun, p. 155-158 DOI: http://dx.doi.org/10.14195/1984-249X_14_11
* Universidade Federal da Bahia. (ordepserra@gmail.com)
Ordep José Trindade Serra

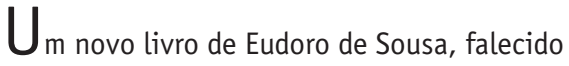
em 1987, representa, sem dúvida, uma bela surpresa: a essa altura, já ninguém o esperava, mesmo porque não se tinha notícia segura de obra remanescente em seu espólio. Todavia, estudiosos dedicados descobriram textos inéditos do saudoso helenista, conservados graças ao zelo de seu discípulo Fernando Bastos (também já falecido) e da viúva deste. Trata-se de sumários de um célebre curso que Eudoro ministrou na década de 1960 (mais precisamente, em 1965) sobre " 0 tema do Inferno nas Literaturas Clássicas: das catábases Sumero-Acadianas até Dante Alighieri." Destinado aos alunos do Instituto de Letras da Universidade de Brasília, o curso assim intitulado atraiu ouvintes de diferentes unidades, como sempre acontecia quando se espalhava a notícia de que Eudoro de Sousa daria lições. 0 brilho de suas aulas irradiava-se no meio universitário, com frequência transcendendo o campus. E provocava sempre um efeito duradouro sobre seu público. Desde sua chegada à nova capital Eudoro fizera-se uma estrela da universidade nascente, um mestre que fascinava seu auditório. No entanto, mesmo levando-se em conta o sucesso que sempre alcançavam as preleções do mestre luso-brasileiro, pode-se dizer que o curso eudoriano sobre as catábases teve um impacto fora 
do comum. Merece o título de "lendário" que lhe deu Marcus Mota no Prefácio do livro em tela: permanece na lembrança dos que o assistiram e mesmo na memória de quem só teve ciência dele de forma indireta, pelo testemunho dos alunos privilegiados.

Quem esteve presente a essas aulas dificilmente as olvidará. Mais de meio século depois, eu as recordo muito bem. E me espanto ao dar-me conta de que ainda sinto o impacto de uma série de preleções que, a rigor, não se completou. Por motivo de saúde, Eudoro não chegou ao termo que tinha previsto: as últimas aulas desse curso foram dadas por José Xavier de Melo Carneiro, que na época concluía seu mestrado no Centro de Estudos Clássicos e, no papel de Instrutor, encarregou-se do comentário de textos selecionados pelo orientador. Por outro lado, também se pode dizer que 0 dito curso teve uma continuidade extra-curricular: prolongou-se em alguns dos seminários que Eudoro dirigiu no CEC, destinados ao pequeno círculo de professores e estudantes ligados de forma direta a este Centro, mas com a participação de ouvintes de variada procedência. Recordo-me de uma sessão que teve início com a leitura de um trecho da Divina Comédia, o Canto V do Inferno, por um professor italiano para isso convidado (o Professor Ivo Perugini). Nessa ocasião Eudoro nos brindou ricas lições sobre Dante e Virgílio. De certo modo, fez então o arremate que o curso sobre as catábases não tivera.

0 presente livro, editado com capricho por Marcus Mota e Gabriele Cornelli, tem especial valor histórico. Registra um momento importante da acidentada saga da UnB, documenta um estágio muito rico da evolução das ideias de um pensador notável, opera o resgate de uma passagem brilhante da história dos Estudos Clássicos no Brasil. Os responsáveis por sua edição, ambos professores da Universidade de Brasília, brindam-na com o resgate de um luminoso fragmento de sua memória, que parecia perdido; fazem uma ponte entre o velho CEC e o Núcleo de Estudos Clássicos (NEC) de que ambos fazem parte. Eudoro de Sousa certamente ficaria feliz se pudesse saber que seu projeto afinal vingou e em sua Universidade dois destacados helenistas, de projeção internacional, trabalharam com afinco para reconstituir um seu precioso trabalho.
Como se sabe, o CEC foi brutalmente extinto por um interventor tacanho que ocupou a reitoria da UnB nos anos mais torvos da Ditadura. Por sorte, o projeto acalentado por Eudoro de Sousa de implantar os estudos clássicos no solo candango renasceu. Este livro mostra a consciência que têm os novos helenistas da UnB do valor de uma tradição preciosa, que de fato merecem capitalizar. Seu empenho em fazê-la reviver mostra que o NEC faz jus à legenda do CEC.

Começarei esta resenha dando notícia do curso que originou o livro em pauta, curso que tive o privilégio de assistir. Orgulho-me de ter colaborado, embora humildemente, com sua realização. Eudoro encarregou-me de fazer a tradução (do inglês) de dois textos extraídos do ANET, ambos reproduzidos no livro em apreço: o poema que é conhecido como último canto da Epopeia de Gilgamesh (mas na verdade vem a ser uma tradução acadiana de um poema sumério, anexada à epopeia) e o documento acadiano chamado "Uma visão dos Infernos", uma espécie de catábase onírica. (Do mesmo tipo de apocalipse se encontra um belo exemplo na própria Epopeia de Gilgamesh: refiro-me ao "Sonho de Enkidu", legível na Tábula V da "Versão Assíria", texto nas edições modernas complementado por um fragmento hitita editado por E. F. Weidner em 1922). Já da "Descida de Inana" e da "Descida de Ishtar" foram usadas versões do próprio Eudoro, que já tinham sido publicadas, tempos atrás, na revista Diálogos. 0 mestre também me incumbiu de traduzir (do latim) o Canto VI da Eneida, determinando que o fizesse em prosa. Jair Gramacho, então mestrando e instrutor no CEC, traduzira em versos esse famoso Canto, procurando imitar o ritmo do hexâmetro virgiliano. Eudoro, todavia, queria uma versão em prosa, mais clara e "analítica". Não a tenho mais, nem sei o que aconteceu com a de Gramacho. Que eu saiba, esta tampouco foi publicada.

José Xavier de Melo Carneiro fez para o mesmo curso uma tradução muito bonita do Canto XI da Odisseia. A tradução de Agostinho da Silva do Somnium Scipionis (famoso trecho do sexto livro do De republica de Cícero) foi utilizada em comentário, mas acho que não foi disponibilizada para os alunos em apostila. 0 estudo eudoriano sobre " 0 s dois cantos finais d' Os Lusíadas à luz da tradição clássica", que 
consta do Anexo II da publicação em exame, teve redação posterior; mas no curso Eudoro falou, sim, da epopeia camoniana.

É claro que esses Sumários não reproduzem na íntegra o curso a que se destinaram. Eudoro era um mestre muito criativo e suas aulas the serviam também para refletir em voz alta, amadurecer suas ideias, construir suas teses. Eram, a um tempo, exposição e estudo. Por outro lado, o projeto do curso não se encerrou nele, antes o transcendeu. Em ricas notas de rodapé, os editores, além de atualizar (e completar) as referências feitas pelo autor a várias obras eruditas, fazem comentários oportunos e suprem informações valiosas, indicando, por exemplo, escritos posteriores de Eudoro de Sousa a que ele incorporou textos extraídos desses ora publicados, ou em que ele "desdobrou-lhes" o conteúdo. Vê-se bem que os temas abordados naquela ocasião o ocuparam por longo tempo, continuaram a ser objeto de suas considerações. Nos ricos apontamentos hoje franqueados ao grande público estão em germe alguns dos ensaios eudorianos mais relevantes.

Chama a atenção a amplitude do campo que o helenista emérito então descortinou. No texto que se tornou o segundo capítulo deste livro ele relaciona os tópicos a serem contemplados no curso: o culto dos mortos (tema do Sumário convertido em segundo capítulo), a religião "de mistério", (assunto dos capítulos terceiro e quarto) o pitagorismo e a doutrina da palingenesia, Orfeu e orfismo, escatologia e gnoseologia platônicas (de que tratam os capítulos seguintes, ou seja, o quinto, o sexto e o sétimo).

$\mathrm{Na}$ Discussão Inicial, que corresponde a uma apresentação do curso e ora corresponde ao capítulo primeiro do livro, o autor tece, de maneira concisa, breves considerações sobre a bibliografia pertinente a fim de mostrar a diversidade das fontes e a variada distribuição dos estudos que interessam ao exame da problemática a ser focalizada, evocando, a propósito, diferentes rubricas encontráveis no Année Philologique. Indica assim a necessidade de um enfoque sistemático de seu objeto - e a novidade de sua empresa.

No capítulo segundo, ele adverte que todos os tópicos assinalados têm a ver com a "poesia dos infernos". Vê-se bem que essa multiforme poesia se tornou o foco das reflexões posteriores do mestre luso-brasileiro: os temas apontados voltaram insistentemente ao cenário de suas pesquisas e alimentaram de modo generoso sua reflexão filosófica.

Neste ponto, sei que o contrario. Na fase derradeira de sua rica vida intelectual, Eudoro não queria ser chamado de filósofo. Chegou a dizer que o projeto denominado "filosofia" se tinha concluído, chegado a seu arremate histórico. Já dera seus frutos, dizia ele. Estava consumado. Devia dar lugar a outra coisa, outro tipo de pensamento ainda por nascer, cuja aurora apenas se anunciava. Nietzsche e o último Heidgger o levaram a esta conclusão. Mas parece-me que tal como eles o mestre de Brasília era ainda filósofo, embora quisesse outra coisa: filosofava de olhos postos no horizonte, procurando mais além um novo espaço. Em suma, fez-se um pensador liminal, transformado intimamente pelo tema que o fascinou. Bem o mostra o tratamento que ele deu a esta problemática, ao reconstruí-la de um modo novo. De fato, ele não abordou o tema das catábases apenas na perspectiva da história da religião, ou só no âmbito da antropologia, isto é, no plano transcultural em que a situou de forma provocativa. Nessa reconstrução, Eudoro de Sousa foi muito além de uma exposição erudita cingida ao campo da Antiguidade "mediterrânea", como (quase) chegou a ser a breve panorâmica esboçada por Ganschnietz no artigo "Katábasis" da RE (vol. X, 2359 sq. A tradução desse verbete, feita por Xavier Carneiro, também foi entregue em apostila aos alunos do famoso curso). Além de dar-lhe maior alcance, recorrendo a notáveis paralelos etnográficos e examinando-os de modo a pôr o problema em termos efetivamente trans-históricos, Eudoro tomou 0 mitologema da catábase como ponto de partida para uma reflexão profunda sobre a existência humana. 0 leitor atento deste livro logo perceberá que o autor não se limitou a informar sobre o assunto (como a erudição "às secas" costuma fazer): ele de fato o problematizou, e é isso que confere a seu estudo um valor especial tanto para a história como para a antropologia. E, convenhamos, para a filosofia.

0 interesse antropológico da proposta de Eudoro não reside meramente em seu recurso a teses de Adolph Jensen, de que ele parece ter sido o 
primeiro a dar notícia no Brasil. Muito mais importa, repito, o modo como ele pôs o problema, o alcance transcultural que the deu.

Se ficamos no Ocidente, no horizonte da sua história, não é difícil mostrar que a obra dantesca de modo nenhum estanca, no campo literário, a recorrência do tema das catábases. (Escusado lembrar que ele se manteve bem vivo, no campo religioso, ao longo da variada trajetória das igrejas cristãs: baste a constatação de que, por notável exemplo, o Credo de Niceia o recorda todos os dias aos católicos). Creio ter mostrado em meu livro "Antropologia Infernal" (SERRA, 2002) a extraordinária vitalidade do referido tópos, examinando textos de Lewis Carrol, Borges, Pávich.

Parece-me claro também que este tema se entrelaça com a grande trama da apocalíptica. Embora esta seja usualmente pesquisada em bases historiográficas e nos limites do judeo-cristianismo, aproximações com outros domínios culturais são facilmente encontráveis.

Volto, porém, ao que afirmei mais acima: Eudoro de Sousa fez do tema das catábases o ponto de partida para uma reflexão sobre a existência humana e sobre o mundo que ao homem corresponde. No livro em discussão ele apenas abre caminho para essa abordagem, quando discute a a transposição platônica de motivos órficos e dos ritos de mistério. Já em seu Mitologias (SOUSA, 2004), livro que escreveu bem mais tarde, ele medita sobre essa vertente mítica de uma forma nova, em estilo eloquente, quase arrebatado: cf. ibidem cap. 2, parágrafos 32-40. Em certo trecho (ver op. cit. parágrafo 33), o mestre de Brasília recorre ao poema da Descida de Inana aos Infernos para explicar a condição do homem, cifrada em sua ambígua relação com 0 divino. 0 mito é então tomado como interpretante da situação existencial que define a humanidade, ou configura, como também se poderia dizer, o estatuto ontológico dos homens.

Nessa altura o discurso do pensador assume um tom quase oracular. Eudoro previne, quase no fim do referido ensaio (no seu parágrafo 64), que esta sua obra tem um novo sentido: “Tudo quanto para trás ficou escrito é mitologia e não quis ser outra coisa". Mas trata-se, evidentemente, de um tipo novo de mitologia, nascida de um projeto hermenêutico de que a raiz primeira, segundo creio, se acha no estudo agora dado a público. Este lavrou-se, porém, numa linguagem bem diferente: clara, sóbria, de uma economia que nada deve ao objetivo prático do apontamento, antes se estriba em zelosa busca de precisão. É que mesmo em simples Sumários de Curso o Professor Emérito responsável pela primeira floração dos estudos clássicos na UnB era capaz de cultivar um estilo conciso, elegante, com algo da discreta harmonia do seu admirado Isócrates. (Já nas suas últimas obras sua escrita se modifica: torna-se mais colorida, apaixonada. Em certas passagens, ganha um esplendor barroco, que o aproxima do tom solene, majestoso, dos sermões de Antônio Vieira).

$\mathrm{Na}$ reflexão eudoriana sobre as catábases de que o livro em apreço mostra o ponto de partida também se acha em germe a rica, original e fecunda exploração que ele fez do tema da "mitologia do horizonte", objeto de uma sua obra prima aparecida uma década depois. Encontro um sinal disso na revelação que me fez o caro mestre: disse-me Eudoro que seu Horizonte e Complementariedade (SOUSA, 1975) teve início no trecho que, na redação final do livro, corresponde ao parágrafo 50 (p. 77). Nesse trecho ele inicia uma discussão extraordinariamente rica do Poema de Parmênides. Ora, é difícil negar que a imagem regente do poema, a viagem do filósofo guiado por uma deusa, segue o modelo simbólico de um apocalipse cujo viático vem a ser uma espécie de catábase. Eudoro afirma então (P. 87) que para descortinar o verdadeiro sentido do Proêmio do poema parmenídeo torna-se necessário ter em mente que “o mistério do horizonte preludia à codificação lógica do mistério do Ser". Posto isso, e apoiando-se em Burkert (1969), avança a hipótese de que “a catábase de Pitágoras seria o pressuposto ou 0 antecedente de uma catábase de Parmênides." Vem a ser ineludível a conclusão de que o dito Proêmio corresponde a uma catábase.

Basta lembrá-lo para que se advirta a importância do escrito em comento. 0 curso que the deu origem foi seminal para o Mestre e também para seus alunos. Os sumários de aparência despretensiosa encerram uma riqueza muito grande. Chamo a atenção para os seus três últimos capítulos: o quinto, rico 
de considerações luminosas sobre os Endmythen platônicos, traz em anexo a tradução de um trecho da Sétima Epístola do filósofo da Academia; o sexto discute o que bem pudera denominar-se "a questão órfica", isto é, o debate entre os helenistas que, na sequela de Willamowitz-Moellendorf, negaram a existência do orfismo e os que não acataram essa rejeição. Eudoro toma partido decididamente pelos últimos, isto é, pelos que reconheceram a consistência do thesaurus "órfico". De modo convincente sustenta ele ainda, no capítulo derradeiro, que desse legado serviu-se Platão, transformando-o, por certo, com sua inegável originalidade: reconhece a presença da herança de Orfeu e Pitágoras na gnoseologia e na escatologia platônicas.

Em suma, o livro que traz de volta a poderosa reflexão de Eudoro de Sousa em um momento axial de sua carreira de helenista e pensador encerra, em prosa sucinta, clara e elegante, uma riqueza de ideias frutíferas e uma abordagem original de temas do mais alto interesse não só para os especialistas nos estudos clássicos como para todos os interessados nas humanidades, no sentido mais amplo do termo. Chega ao público em momento oportuno, na altura em que as atenções dos helenistas se voltam para este tema com renovado interesse, como mostra a realização, entre 2 e 5 de maio deste ano de 2014, em Québec e Montréal, de um colóquio internacional sobre o assunto (Colloque International Katábasis) organizado pelo Prof. Pierre Bonnechère e pela Dra. Gabriela Cursaru, com a colaboração de eminentes mestres de quatro instituições universitárias de peso: os professores Alberto Bernabé, da Universidade Complutense de Madri, Bill Gladhill e Lynn Kozak, da MacGill, Anne-France Morand, da Université Laval (Quebec) e Jean Michel Roessli, da Concordia University (Montréal). A publicação das atas desse colóquio certamente vai provocar uma nova e produtiva onda de debates sobre o assunto. É uma boa hora para recordar estas lições de nosso Eudoro.

\section{SIGLAS (OBRAS DE REFERÊNCIA CITADAS)}

ANET - Ancient Near Easter Texts relating to the Old Testament. Ed. J. B. PRITCHARD. Princeton: New Jersey University Press, 1950.

RE - Paulys Realencyclopädie der Altertumswissenschaft. Eds. PAULY, A. F. VON; WISSOWA, G.; KROLL, W. Stuttgart: J. B. Metzler, 1894-1972.

\section{OUTRAS REFERÊNCIAS BIBIBLIOGRÁFICAS}

BURKERT, W. (1928). Das Proömium des Parmenides und die Katabasis des Pythagoras. In: Phronesis, n. 14.

SERRA, 0. (2002). Veredas: Antropologia Infernal. Salvador, EDUFBA.

SOUSA, E. (1975). Horizonte e complementariedade. Brasília, Editora da UnB.

(2004). Mitologias. Lisboa, Imprensa Nacional

- Casa da Moeda

Recebido em setembro de 2014, aprovado em outubro de 2014. 